\title{
The Current Status of Decompressive Craniectomy in Traumatic Brain Injury
}

\author{
Angelos G. Kolias ${ }^{1,2} \cdot$ Edoardo Viaroli $^{3}$ • Andres M. Rubiano ${ }^{2,4} \cdot$ Hadie Adams ${ }^{1} \cdot$ Tariq Khan $^{2,5} \cdot$ Deepak Gupta $^{2,6}$. \\ Amos Adeleye $^{2,7,8} \cdot$ Corrado laccarino $^{9}$. Franco Servadei ${ }^{10} \cdot$ Bhagavatula Indira Devi $^{2,11} \cdot$ Peter J. Hutchinson ${ }^{1,2}$
}

Published online: 1 September 2018

(C) The Author(s) 2018

\begin{abstract}
Purpose This review describes the evidence base that has helped define the role of decompressive craniectomy (DC) in the management of patients with traumatic brain injury (TBI).

Recent Findings The publication of two randomized trials (DECRA and RESCUEicp) has strengthened the evidence base. The DECRA trial showed that neuroprotective bifrontal DC for moderate intracranial hypertension is not helpful, whereas the RESCUEicp trial found that last-tier DC for severe and refractory intracranial hypertension can significantly reduce the mortality rate but is associated with a higher rate of disability. These findings have reopened the debate about (1) the indications for DC in various TBI subtypes, (2) alternative techniques (e.g., hinge craniotomy), (3) optimal time and material for cranial reconstruction, and (4) the role of shared decision-making in TBI care. Additionally, the role of primary DC when evacuating an acute subdural hematoma is currently undergoing evaluation in the context of the RESCUE-ASDH randomized trial.

Summary This review provides an overview of the current evidence base, discusses its limitations, and presents a global perspective on the role of DC, as there is growing recognition that attention should also focus on low- and middle-income countries due to their much greater TBI burden.
\end{abstract}

Keywords Neurosurgery $\cdot$ Neurotrauma $\cdot$ Decompression $\cdot$ Cranioplasty $\cdot$ Cisternostomy

\section{Introduction}

Traumatic brain injury (TBI) remains a major public health problem worldwide. It is a leading cause of mortality and disability across the globe, with low- and middle-income countries

This article is part of the Topical Collection on Traumatic Brain Injury

Angelos G. Kolias

ak721@cam.ac.uk

1 Department of Clinical Neurosciences, Division of Neurosurgery, Addenbrooke's Hospital \& University of Cambridge, Cambridge CB2 0QQ, UK

2 NIHR Global Health Research Group on Neurotrauma, University of Cambridge, Cambridge, UK

3 Department of Clinical Neurosciences, Service of Neurosurgery, University Hospital of Lausanne (CHUV), Lausanne, Switzerland

4 Neuroscience Institute, INUB-MEDITECH Research Group, El Bosque University, Bogotá, Colombia

5 Department of Neurosurgery, North West General Hospital and Research Center, Peshawar, Pakistan
(LMICs) facing the greatest disease burden [1•]. Brain swelling and intracranial hypertension are well-recognized secondary insults associated with increased mortality and poorer outcomes.

Decompressive craniectomy (DC) refers to the practice of removing a large bone flap and opening the underlying dura in

6 Department of Neurosurgery, Neurosciences Centre, All India Institute of Medical Sciences, New Delhi, India

7 Department of Surgery, Division of Neurological Surgery, College of Medicine, University of Ibadan, Ibadan, Nigeria

8 Department of Neurological Surgery, University College Hospital, Ibadan, Nigeria

9 Department of Neurosurgery, Azienda Ospedaliero Universitaria di Parma, Parma, Italy

10 Department of Neurosurgery, Humanitas University and Research Hospital, Milan, Italy

11 Department of Neurosurgery, National Institute of Mental Health and Neurosciences (NIMHANS), Bangalore, India 
order to control brain swelling and raised intracranial pressure (ICP). This review aims to present the evidence base concerning the role of DC following TBI, to identify areas of uncertainty, and to discuss future directions.

\section{Historical Perspectives}

There is evidence that the practice of trephination (a word coming from Ancient Greek trypanon: to drill) dates back to around 10,000 B.C. [2]. The first known written report concerning the use of trephination dates back to Ancient Greece, more precisely to Hippocrates, who defined the indications for trephination in relation to different types of skull fractures $[2,3]$. The practice of trephination continued during the Roman era, Middle Ages, and Renaissance. One physician whose work was particularly significant was Berengario da Carpi (1466-1530). He provided the first classification of head trauma and its outcome in relation to surgical techniques [4].

In the modern era, Theodor Kocher first described the necessity of opening the skull in the presence of increased intracranial pressure: "if there is no cerebrospinal fluid (CSF) pressure, but brain pressure exists, then pressure relief must be achieved by opening the skull" [5]. The first results of Kocher's doctrine were published by Harvey Cushing in 1908, who reported a drastic reduction in TBI mortality from 50 to $15 \%$ after subtemporal DC [6]. During the twentieth century, different DC techniques were described (hemicraniectomy, circumferential, bifrontal), but lack of consensus about indications and significant variation in outcomes paved the way for randomized trials in the beginning of the twenty-first century $[7,8]$.

\section{Definitions}

Hemicraniectomy, also known as unilateral DC or frontotemporoparietal craniectomy, refers to the removal of a large frontotemporoparietal bone flap, whereas bifrontal DC refers to the removal of a bone flap extending from the floor of the anterior cranial fossa to the coronal suture, and to the middle cranial fossa floor bilaterally. Wide opening of the dura is a necessary part of the procedure.

\section{Subtypes of TBI in Which DC Is Used}

- A DC is most frequently undertaken in comatose patients with an acute subdural hematoma (ASDH) and associated brain swelling in the early phase after injury [9-11]. In this group of patients, the ASDH is evacuated and a large bone flap is left out either because the brain is bulging beyond the inner table of the skull or because increasing brain swelling (e.g., in a patient with large cerebral contusions) is anticipated in the postoperative period. This type of DC is termed primary and is most frequently a unilateral hemicraniectomy. With regard to timing from injury, a primary DC is usually undertaken within the first $24 \mathrm{~h}$, but in some papers the time window extends to the first 48-72 h [12•, 13].

- A DC can also be undertaken in comatose patients who have parenchymal hemorrhage or contusions (usually frontotemporal) with substantial mass effect. This usually manifests as midline shift (>5 mm) and/or uncal herniation in the case of predominantly unilateral contusions or obliterated basal cisterns in the case of bilateral contusions. Such patients may initially receive ICP monitoring (if available) and proceed to a DC later if their ICP becomes difficult to control. This type of DC is termed secondary and can be unilateral (for predominantly unilateral pathology) or bifrontal (for predominantly bilateral pathology). Alternatively, patients with severe mass effect and clinical signs of herniation (such as anisocoria) may receive a DC early after injury without prior monitoring of ICP, especially in areas with low availability of neuromonitoring resources $[14,15 \bullet]$.

- Patients who have had a craniotomy (i.e., bone flap replaced at end of procedure) for evacuation of an intracranial hematoma in the early phase after injury occasionally undergo a subsequent DC if their ICP becomes difficult to control or if they deteriorate neurologically with radiological evidence of increasing mass effect. This usually occurs in patients in whom coexisting contusions are blossoming.

- Less frequent indications include closed TBI with diffuse brain swelling without any significant hematomas/contusions, gunshot wound with gross hemorrhage and swelling; and severe blast injury with gross swelling [16-18].

Overall, primary DC at the same time as evacuation of a hematoma is the most frequent scenario for performance of DC [19•]. Secondary DC undertaken after a period of ICP monitoring in order to control refractory elevation of ICP and/or to treat clinical or radiological deterioration is a less frequent indication.

\section{Strengthening the Evidence Base}

In the 1990s, after advances in imaging, prehospital, and intensive care led to improvements in TBI management, the importance of developing the evidence base for DC by conducting robust studies became apparent.

It is widely accepted that well-planned experimental studies can provide robust evidence to inform clinical practice. 
When one is interested in evaluating the effectiveness of a treatment, a control group, ideally in the context of a randomized controlled trial (RCT), is necessary. Through random assignment of individuals, the treatment and control groups are likely to be balanced in both observable and nonobservable characteristics. Consequently, we can be fairly confident that any differences in outcome between the two groups are due to the experimental effect of exposure to the treatment [20].

However, RCTs may not always be feasible for practical or ethical reasons. Additionally, treatments with dramatic effects that are unlikely to have resulted from inadequately controlled biases do not need to be subjected to a RCT. Such an example from the field of TBI would be evacuation of a substantial extradural hematoma in a patient who is neurologically compromised. Furthermore, a number of potential difficulties, such as lack of clinical equipoise, strong patient and clinician preferences, imbalance in surgical expertise, cross-over between groups, and difficulty with blinding, may render surgical trials particularly challenging [21].

New approaches, such as comparative effectiveness research (CER), have become popular in recent years. Nonexperimental CER studies-such as the CENTER-TBI project (https://www.center-tbi.eu/) - aim to utilize heterogeneity in care provision and outcomes to compare the effectiveness of treatments that are standard practice in some centers but not in others. Nevertheless, the methodology of non-experimental CER studies and interpretation of their findings remain a work in progress. Therefore, even though these efforts are important and promising, they can only be seen as being complementary to randomized trials. Pragmatic RCTs, which compare two or more treatments in the "real world," are a form of CER, the so-called experimental CER [22]. Although RCTs and nonexperimental CER are both important facets of TBI research, only RCTs are widely accepted as the gold-standard method for assessing the efficacy and effectiveness of therapeutic interventions. Hence, if a question is sufficiently refined to allow the design of an RCT, such a study should be undertaken whenever feasible [23].

\section{Overview of Main Randomized Trials RCT in TBI}

The main randomized trials in the field of DC following TBI are three in number: (1) DECRA trial, which examined the role of neuroprotective, secondary, and bifrontal DC for moderate intracranial hypertension; (2) RESCUEicp trial, which examined the role of last-tier secondary DC for severe and refractory intracranial hypertension; and (3) RESCUEASDH trial, which is examining the role of primary DC for ASDH.
The DECRA trial, for which results were published in 2011, enrolled 155 patients with severe diffuse TBI and moderate intracranial hypertension in three different countries (Australia, New Zealand, and Saudi Arabia) [24••]. Patients were eligible for randomization within the first $72 \mathrm{~h}$ after trauma if the ICP was higher than $20 \mathrm{mmHg}$ for $>15 \mathrm{~min}$ (continuously or intermittently) within a 1 -h period and was not responding to first-tier ICP-lowering interventions. Patients were randomized to bifrontal DC or to continuing medical care. The primary endpoint was the extended Glasgow Outcome Scale (GOSE) score at 6 months. The mortality was similar in both groups (19\% vs $18 \%)$, but more surgical patients had an unfavorable GOSE (70\% vs 51\%; $p=0.02$ ). Following post hoc adjustment for pupil reactivity at baseline, the rate of unfavorable outcome was no longer significantly different between the two arms (adjusted OR 1.90 ; $95 \%$ CI $0.95-3.79$ ). Although DECRA has been widely criticized for various reasons [25], we view it as a valuable trial that addressed a very specific question. On the basis of its findings, we are able to conclude that bifrontal DC should not be used as a neuroprotective measure for moderate posttraumatic intracranial hypertension in well-resourced settings.

The RESCUEicp trial, for which results were published in 2016, enrolled 408 patients with severe and refractory posttraumatic intracranial hypertension in 20 countries [26••]. Patients were eligible for randomization at any time point after trauma if the ICP was higher than $25 \mathrm{mmHg}$ for at least $1 \mathrm{~h}$ and did not respond to first-tier and second-tier ICP-lowering interventions. Patients were randomized to secondary DC (bifrontal DC or hemicraniectomy) or standardized medical therapy (with the option of barbiturates after randomization). The primary endpoint was GOSE score at 6 months. DC resulted in substantially lower mortality ( $26.9 \%$ vs $48.9 \%$ ) but higher rates of vegetative state ( $8.5 \%$ vs $2.1 \%)$, lower severe disability ( $21.9 \%$ vs $14.4 \%)$, and upper severe disability (independent at home; $15.4 \%$ vs $8 \%$ ) than medical care. The rates of moderate disability and good recovery were similar in the two groups. Nevertheless, surgical patients continued improving beyond the 6 months, and at 12 months, $45.4 \%$ of surgical patients had a favorable outcome (upper severe disability or better) compared to $32.4 \%$ in the medical group $(p=0.01)$. These results suggest that secondary DC can be helpful as a last-tier intervention to reduce mortality in the subset of TBI patients with severe and refractory posttraumatic intracranial hypertension. However, caution is needed because approximately $40 \%$ of extra survivors generated by DC will be dependent on others at 12 months. The contrasting results of DECRA and RESCUEicp arise from differences in study hypotheses, eligibility criteria, and therapeutic protocols; the main differences have been summarized in Table 1 [27].

The RESCUE-ASDH trial is currently ongoing. This trial aims to address the paucity of high-quality evidence regarding 
Table 1 Differences between DECRA and RESCUEicp trials

\begin{tabular}{|c|c|c|}
\hline & DECRA & RESCUEicp \\
\hline Recruitment up to $72 \mathrm{~h}$ post-TBI & $100 \%$ of patients & $56 \%$ of patients \\
\hline TBI type & Diffuse injury only & $\begin{array}{l}\text { Diffuse injury and/or mass lesions } \\
\text { (including contusions and evacuated hematomas) }\end{array}$ \\
\hline ICP threshold & $>20 \mathrm{mmHg}$ for $15 \mathrm{~min}$ in $1 \mathrm{~h}$ & $>25 \mathrm{mmHg}$ for at least $1 \mathrm{~h}$ \\
\hline ICP-lowering therapies before randomization & Tier 1 & Tiers 1 and 2 \\
\hline Pooled mortality & $18.7 \%$ & $37.5 \%$ \\
\hline Mortality in DC vs medical group & 19 vs $18 \%$ & 26.9 vs $48.9 \%$ \\
\hline Documented follow-up & 6 months & 6 and 12 months \\
\hline
\end{tabular}

the best surgical strategy (primary DC or craniotomy) for patients with ASDH (Table 2). A previously published survey has shown that a higher percentage of neurosurgeons from other European countries $(48 / 110 ; 44 \%)$ as compared with UK/Irish neurosurgeons $(29 / 138 ; 21 \%)$ use primary DC in more than half of ASDH cases $(p<0.001)$ [28]. A more recent survey of 60 neurosurgeons from the Netherlands and Belgium demonstrated a large variation in the decision to combine ASDH evacuation with a DC [29•]. These results demonstrate that a considerable lack of consensus exists on the indications for primary DC in this context. The RESCUEASDH trial was funded by the UK National Institute for Health Research (NIHR) and was launched in 2014 with the aim of comparing primary DC (bone flap left out) with craniotomy (bone flap replaced and fixed) for patients with a serious TBI undergoing evacuation of an ASDH. Similar to real- world practice, eligible patients are randomized intraoperatively after evacuation of their ASDH. Patients with significant brain swelling preventing safe replacement of the bone flap are not suitable for randomization and are being enrolled in a parallel observational cohort. The study is ongoing, and more than 400 patients have been enrolled in the randomized trial from 35 sites worldwide [23].

Finally, another study that should be mentioned is a randomized trial that took place in five centers in China to compare outcomes after a standard-sized trauma DC $(12 \times 15-\mathrm{cm}$ flap) vs a limited DC $(6 \times 8-\mathrm{cm}$ flap $)$ in severe TBI patients with refractory intracranial hypertension [30•]. The authors recruited 486 patients in total and found that the mortality rate was lower $(26 \%$ vs $35 \%)$ and favorable outcome rate higher (39.8\% vs $28.6 \%)$ after standard trauma DC compared to limited DC $(p<0.05)$.

Table 2 Inclusion, exclusion criteria, and outcome measures of RESCUE-ASDH

\begin{tabular}{|c|c|}
\hline Inclusion criteria & $\begin{array}{l}\text { 1. Adult head-injured patients ( }>16 \text { years) } \\
\text { 2. ASDH on CT } \\
\text { 3. The admitting neurosurgeon feels that the hematoma needs to be evacuated with a large bone flap ( } \geq 11 \text {-cm anteroposterior } \\
\text { diameter) either by a craniotomy or decompressive craniectomy (patients with additional lesions such as intracerebral } \\
\text { hemorrhage/contusions) may be included }\end{array}$ \\
\hline Exclusion criteria & $\begin{array}{l}\text { 1. Bilateral ASDHs both requiring evacuation } \\
\text { 2. Previous enrollment in RESCUE-ASDH study } \\
\text { 3. Severe pre-existing physical or mental disability or severe co-morbidity which would lead to a poor outcome even if the } \\
\text { patient made a full recovery from the head injury }\end{array}$ \\
\hline $\begin{array}{l}\text { Primary outcome } \\
\text { measure }\end{array}$ & Extended Glasgow Outcome Scale (GOSE) at 12 months \\
\hline $\begin{array}{l}\text { Secondary outcome } \\
\text { measures }\end{array}$ & $\begin{array}{l}\text { 1. GOSE at } 6 \text { months } \\
\text { 2. Quality of life (EQ-5D) at discharge from neurosurgical ward, } 6 \text { and } 12 \text { months } \\
\text { 3. Glasgow Coma Scale (GCS) on discharge from the intensive care unit (ICU) and from neurosurgical ward } \\
\text { 4. Length of stay in ICU, neurosurgical and rehabilitation unit } \\
\text { 5. Discharge destination from neurosurgical ward } \\
\text { 6. Mortality } \\
\text { 7. Serious adverse events and surgical complications } \\
\text { 8. Subsequent readmissions within the } 1 \text {-year follow-up period } \\
\text { 9. Return to operating theater for cranial surgery within } 2 \text { weeks after randomization } \\
\text { 10. Hydrocephalus requiring shunt insertion within the } 12 \text { months follow-up period } \\
\text { 11. Therapy intensity level in the ICU } \\
\text { 12. Economic evaluation }\end{array}$ \\
\hline
\end{tabular}




\section{Limitations of Current Evidence Base}

About $90 \%$ of worldwide trauma-related deaths occur in LMICs. However, less than $10 \%$ of the RESCUEicp patient population was enrolled in LMICs (36/408 patients from six countries), whereas all patients in the DECRA study were from high-income countries (HICs). This fact raises some important questions. Firstly, is it possible to extrapolate the results from studies taking place in HICs (where prehospital, acute neurosurgical, and postacute care are generally delivered in a more systematic way) to the results that can be expected in LMICs? Secondly, is it possible for neurosurgeons working in LMICs to follow recommendations derived from the DECRA and RESCUEicp studies, given that ICP monitoring may not be available in their daily practices? Nevertheless, the burden of TBI is much higher in LMICs, and patients are being treated for TBI despite the absence of evidence directly applicable to these countries. These are issues that are receiving further study as part of efforts to improve global neurotrauma care. Such an initiative is the NIHR Global Health Research Group on Neurotrauma, which is supported by the World Federation of Neurosurgical Societies. This international group aims to improve neurotrauma care in LMICs.

Additionally, more attention needs to be paid to the issue of cranial reconstruction (cranioplasty) following DC. Neurological dysfunction associated with large skull defects has been proposed as an important factor that can influence the outcome of patients after DC $[31 \cdot, 32]$. Small, uncontrolled studies suggest that earlier cranioplasty (within three months of DC) may facilitate rehabilitation and may even independently improve long-term outcome [33・•]. From the surgical viewpoint, the tissue planes seem to be more favorable when a cranioplasty is undertaken early. However, due to a longstanding belief that the rate of infection may be higher with earlier cranioplasty, many of these operations are undertaken in a delayed fashion. This is clearly an important area for future research. Additionally, despite the plethora of different materials available for cranioplasty following DC (e.g., titanium, PEEK, hydroxyapatite, and the patient's own bone flap), uncertainty remains as to whether anyone of them is associated with better outcomes [34]. Cranioplasty-related costs differ among various materials, which is an important consideration for LMICs as well as several HICs with state-funded healthcare systems.

Another area of debate is the use of floating or hinged bone flaps as a potential decompressive method for TBI. Floating or hinged bone flaps have the potential to control at least moderate swelling while at the same time obviating the need for a subsequent cranioplasty [35, 36॰]. This is an important consideration in resource-limited settings. These techniques could be evaluated prospectively in randomized controlled studies, as if they are proven to be beneficial, they could advance the care of patients in LMICs.
The opening of basal cisterns (cisternostomy) has also been suggested as a surgical maneuver for managing posttraumatic brain swelling and elevated ICP [37]. However, this technique requires a microscope and instruments for microneurosurgery, which may limit its utility in resource-constrained settings. Additionally, the fact that an external cisternal drain is left in situ (with CSF drainage of 150-200 $\mathrm{ml} /$ day for 6 days in a recent case report) [38] suggests that the therapeutic effect of cisternostomy may be mediated at least in part by CSF drainage. A much simpler and faster method for achieving CSF drainage is an external ventricular drain (ventriculostomy), but due to the additional hypothesized benefits of cisternostomy, it has become clear that the only way to determine the utility of cisternostomy is through the conduct of randomized trials. Despite the criticism that is often directed to randomized surgical trials, they remain the optimal study design for rigorous evaluation of surgical interventions, techniques, and devices [39, 40].

Finally, it should be emphasized that the perspectives of patients and their families should always be considered when determining the degree of "acceptable" disability. Additionally, the degree of "acceptable" disability varies from person to person and is dependent on many factors, such as culture, social environment, and religion. Therefore, the indirect input of the patient (as best as is possible) and of families is very important when determining the degree of acceptable disability for an individual, and consequently whether a DC should be considered [41, 42].

\section{Conclusions}

Several TBI subtypes associated with brain swelling and/or raised ICP can be managed by DC. However, current evidence from multicenter clinical trials suggests that (1) early neuroprotective bifrontal DC for mild to moderate intracranial hypertension is not superior to medical management for patients with diffuse TBI, and (2) unilateral or bifrontal DC used as a last-tier therapy for patients with severe, sustained, and refractory posttraumatic intracranial hypertension leads to a substantial mortality reduction but increases disability (both lower and upper severe disability) compared to medical management. The RESCUE-ASDH trial is currently open and aims to define the role of primary DC for patients with acute subdural hematomas and swelling. The global neurosurgical community needs to consider the roles of DC, cranioplasty, and other decompressive procedures (such as floating or hinge craniotomy) not just in HICs but also, and perhaps more importantly, in LMICs due to their much greater TBI burden.

Acknowledgments Angelos Kolias is supported by a Clinical Lectureship, School of Clinical Medicine, University of Cambridge. Peter Hutchinson is supported by a Research Professorship from the 
National Institute for Health Research (NIHR), the NIHR Cambridge Biomedical Research Centre, a European Union Seventh Framework Program grant (CENTER-TBI; grant no. 602150), and the Royal College of Surgeons of England. The NIHR Global Health Research Group on Neurotrauma was commissioned by the NIHR using Official Development Assistance (ODA) funding (project 16/137/105). The views expressed in this publication are those of the author(s) and not necessarily those of the NHS, National Institute for Health Research or the Department of Health.

\section{Compliance with Ethical Standards}

Conflict of Interest Drs Kolias, Khan, Gupta, Iaccarino, Servadei, Devi, and Hutchinson are involved as investigators with the RESCUE-ASDH trial (www.rescueasdh.org; accessed 28 June 2018). The RESCUE-ASDH project is funded by the National Institute for Health Research (NIHR HTA 12/35/57). The views expressed are those of the authors and are not necessarily those of the NHS, the NIHR, or the Department of Health. Drs Viaroli and Iaccarino report personal fees outside the submitted work for consultancy from Finceramica S.p.A. No other conflicts of interest are reported.

Human and Animal Rights and Informed Consent All reported studies/ experiments with human or animal subjects performed by the authors have been previously published and complied with all applicable ethical standards (including the Helsinki declaration and its amendments, institutional/national research committee standards, and international/national/institutional guidelines).

Open Access This article is distributed under the terms of the Creative Commons Attribution 4.0 International License (http:// creativecommons.org/licenses/by/4.0/), which permits unrestricted use, distribution, and reproduction in any medium, provided you give appropriate credit to the original author(s) and the source, provide a link to the Creative Commons license, and indicate if changes were made.

\section{References}

Papers of particular interest, published recently, have been highlighted as:

- Of importance

•. Of major importance

1. Dewan MC, Rattani A, Gupta S, et al. Estimating the global incidence of traumatic brain injury. J Neurosurg. 2018:1-18. https:// doi.org/10.3171/2017.10.JNS17352. A recent paper attempting to quantify the global burden of TBI.

2. Kshettry VR, Mindea SA, Batjer HH. The management of cranial injuries in antiquity and beyond. Neurosurg Focus. 2007;23(1):E8. Review

3. Panourias IG, Skiadas PK, Sakas DE, Marketos SG Hippocrates: a pioneer in the treatment of head injuries. Neurosurgery 2005;57(1): 181-189; discussion 181-9.

4. Di Ieva A, Gaetani P, Matula C, et al. Berengario da Carpi: a pioneer in neurotraumatology. J Neurosurg. 2011;114(5):1461-70. https:// doi.org/10.3171/2010.10.JNS101331.

5. Kocher T. Hirnerschütterung, Hirndruck und chirurgische Eingriffe bei Hirnkrankheitende. In: Hölder A, editor. Die Therapie des hirndruckes. Vienna: A. Hölder; 1901. p. 262-6. Germany.
6. Cushing HI. Subtemporal decompressive operations for the intracranial complications associated with bursting fractures of the skull. Ann Surg. 1908;47(5):641-644.1.

7. Polin RS, Shaffrey ME, Bogaev CA, Tisdale N, Germanson T, Bocchicchio B, et al. Decompressive bifrontal craniectomy in the treatment of severe refractory posttraumatic cerebral edema. Neurosurgery. 1997;41:84-92.

8. Whitfield PC, Patel H, Hutchinson PJ, et al. Bifrontal decompressive craniectomy in the management of posttraumatic intracranial hypertension. Br J Neurosurg. 2001;15:500-7.

9. Kolias AG, Kirkpatrick PJ, Hutchinson PJ. Decompressive craniectomy: past, present and future. Nat Rev Neurol. 2013;9: 405-15.

10. Servadei F, Compagnone C, Sahuquillo J. The role of surgery in traumatic brain injury. Curr Opin Crit Care. 2007;13(2):163-8.

11. Sahuquillo J, Arikan F. Decompressive craniectomy for the treatment of refractory high intracranial pressure in traumatic brain injury. Cochrane Database Syst Rev. 2006:CD003983.

12. Picetti E, Caspani ML, Iaccarino $C$, et al. Intracranial pressure monitoring after primary decompressive craniectomy in traumatic brain injury: a clinical study. Acta Neurochir (Wien). 2017;159(4): 615-22. https://doi.org/10.1007/s00701-017-3118-z. Retrospective single-center study which found that intracranial hypertension frequently occurs even after primary DC

13. Timofeev I, Santarius T, Kolias AG, et al. Decompressive craniectomy - operative technique and perioperative care. Adv Tech Stand Neurosurg. 2012;38:115-36.

14. Rubiano AM, Villarreal W, Hakim EJ, Aristizabal J, Hakim F, Dìez JC, et al. Early decompressive craniectomy for neurotrauma: an institutional experience. Ulus Travma Acil Cerrahi Derg. 2009;15(1):28-38.

15. Charry JD, Rubiano AM, Nikas CV, et al. Results of early cranial decompression as an initial approach for damage control therapy in severe traumatic brain injury in a hospital with limited resources. J Neurosci Rural Pract. 2016;7(1):7-12. https://doi.org/10.4103/ 0976-3147.172151. Recent single-center study examining the role of damage control early DC in resource-limited settings.

16. Charry JD, Rubiano AM, Puyana JC, Carney N, David Adelson P. Damage control of civilian penetrating brain injuries in environments of low neuro-monitoring resources. Br J Neurosurg. 2016;30(2):235-9. https://doi.org/10.3109/02688697.2015. 1096905.

17. Bell RS, Mossop CM, Dirks MS, Stephens FL, Mulligan L, Ecker $\mathrm{R}$, et al. Early decompressive craniectomy for severe penetrating and closed head injury during wartime. Neurosurg Focus. 2010;28(5):E1. https://doi.org/10.3171/2010.2.FOCUS1022.

18. Figaji AA, Fieggen AG, Peter JC. Early decompressive craniotomy in children with severe traumatic brain injury. Childs Nerv Syst. 2003;19(9):666-73.

19. Kramer AH, et al. Decompressive craniectomy in patients with traumatic brain injury: are the usual indications congruent with those evaluated in clinical trials? Neurocrit Care. 2016;25:10-9. Recent paper examining the indications for $\mathrm{DC}$ in a realworld setting.

20. Sackett DL, Rosenberg WM, Gray JA, et al. Evidence based medicine: what it is and what it isn't. BMJ. 1996;312:71-2.

21. Ergina PL, Cook JA, Blazeby JM, Boutron I, Clavien PA, Reeves $\mathrm{BC}$, et al. Challenges in evaluating surgical innovation. Lancet. 2009;374:1097-104.

22. Chalkidou K, Tunis S, Whicher D, Fowler R, Zwarenstein M. The role for pragmatic randomized controlled trials (pRCTs) in comparative effectiveness research. Clin Trials. 2012;9(4):436-46.

23. Kolias AG, Adams H, Timofeev I, Czosnyka M, Corteen EA, Pickard JD, Turner C, Gregson BA, Kirkpatrick PJ, Murray GD, Menon DK, Hutchinson PJ Decompressive craniectomy following traumatic brain injury: developing the evidence base. Br J 
Neurosurg 2016;30(2):246-250. doi: https://doi.org/10.3109/ 02688697.2016.1159655. Review.

24.• Cooper DJ, Rosenfeld JV, Murray L, et al. Decompressive craniectomy in diffuse traumatic brain injury. N Engl J Med. 2011;364:1493-502. The full results of the DECRA randomized trial of early bifrontal DC.

25. Iaccarino $\mathrm{C}$, Schiavi P, Servadei F. Decompressive craniectomies: time to discuss not the DECRA study but the comments to the DECRA study. World Neurosurg. 2013;79(1):78-9. https://doi. org/10.1016/j.wneu.2012.10.061.

26.• Hutchinson PJ, et al. Trial of decompressive craniectomy for traumatic intracranial hypertension. N Engl J Med. 2016;375:1119-30. https://doi.org/10.1056/NEJMoa1605215. The full results of the RESCUEicp randomized trial.

27. Hutchinson PJ, Kolias AG, Menon DK. Craniectomy for traumatic intracranial hypertension. N Engl J Med. 2016;375(24):2403-4. https://doi.org/10.1056/NEJMc1613479.

28. Kolias AG, Belli A, Li LM, Timofeev I, Corteen EA, Santarius T, et al. Primary decompressive craniectomy for acute subdural haematomas: results of an international survey. Acta Neurochir. 2012;154(9):1563-5. https://doi.org/10.1007/s00701-012-1349-6.

29. van Essen TA, de Ruiter GC, Kho KH, et al. Neurosurgical treatment variation of traumatic brain injury: evaluation of acute subdural hematoma management in belgium and the netherlands. J Neurotrauma. 2017;34(4):881-9. https://doi.org/10.1089/neu. 2016.4495. A recent survey demonstrating variation in the management of patients with acute subdural hematomas.

30. Jiang JY, Xu W, Li WP, et al. Efficacy of standard trauma craniectomy for refractory intracranial hypertension with severe traumatic brain injury: a multicenter, prospective, randomized controlled study. J Neurotrauma. 2005;22(6):623-8. A randomized trial of large vs small unilateral DC for patients with elevated ICP after TBI.

31. Honeybul S, Janzen C, Kruger K, et al. The incidence of neurologic susceptibility to a skull defect. World Neurosurg. 2016;86:147-52. https://doi.org/10.1016/j.wneu.2015.09.081. A recent study of 50 patients assessed $72 \mathrm{~h}$ before and 7 days after cranioplasty, finding that improvements after cranioplasty were more likely to occur in the domain of cognitive function than motor function.
32. Honeybul S. Neurological dysfunction due to large skull defect: implications for physiotherapists. J Rehabil Med. 2017;49(3): 204-7. https://doi.org/10.2340/16501977-2209. Review

33.• Malcolm JG, Rindler RS, Chu JK, et al. Early cranioplasty is associated with greater neurological improvement: a systematic review and meta-analysis. Neurosurgery. 2018;82(3):278-88. https://doi. org/10.1093/neuros/nyx182. A recent systematic review finding that early cranioplasty within 3 months after DC may lead to greater neurological improvement compared to delayed cranioplasty.

34. Shah AM, Jung H, Skirboll S. Materials used in cranioplasty: a history and analysis. Neurosurg Focus. 2014;36(4):E19. https:// doi.org/10.3171/2014.2.FOCUS13561. Review

35. Gutman MJ, How E, Withers T. The floating anchored craniotomy. Surg Neurol Int. 2017;8:130. https://doi.org/10.4103/sni.sni_460_ 16. eCollection 2017

36. Adeleye AO. Clinical and radiologic outcome of a less invasive, low-cost surgical technique of osteoplastic decompressive craniectomy. J Neurol Surg A Cent Eur Neurosurg. 2016;77(2): 167-75. https://doi.org/10.1055/s-0035-1566115. A recent paper presenting encouraging results with the use of hinge craniotomy.

37. Giammattei L et al. Current perspectives in the surgical treatment of severe traumatic brain injury. World Neurosurg. https://doi.org/10. 1016/j.wneu.2018.05.176.

38. Cherian I, Bernardo A, Grasso G. Cisternostomy for traumatic brain injury: pathophysiologic mechanisms and surgical technical notes. World Neurosurg. 2016;89:51-7.

39. Gelijns AC, Ascheim DD, Parides MK, Kent KC, Moskowitz AJ. Randomized trials in surgery. Surgery. 2009 Jun;145(6):581-7. https://doi.org/10.1016/j.surg.2009.04.003.

40. McCulloch P, Feinberg J, Philippou Y, et al. Progress in clinical research in surgery and IDEAL. Lancet. 2018; https://doi.org/10. 1016/S0140-6736(18)30102-8.

41. Menon DK, Kolias AG, Servadei F, Hutchinson PJ. Survival with disability. Whose life is it, anyway? Br J Anaesth. 2017;119(5): 1062-3. https://doi.org/10.1093/bja/aex374.

42. Smith M. Refractory intracranial hypertension: the role of decompressive craniectomy. Anesth Analg 2017;125(6):1999-2008. doi: https://doi.org/10.1213/ANE.0000000000002399. Review. 